\title{
Effective removal of nutrients from wastewater
}

\author{
Olga Ruzhitskaya ${ }^{1, *}$, Elena Gogina $^{2}$ and Varvara Shmalko ${ }^{2}$ \\ ${ }^{1}$ Peoples' Friendship University of Russia, 6 Miklukho-Maklaya St., Moscow, 117198, Russia \\ ${ }^{2}$ Moscow State University of Civil Engineering, Department of water supply and wastewater \\ treatment, 26, Yaroslavskoe shosse, Moscow, 129337, Russia
}

\begin{abstract}
The current information in the field of wastewater from phosphates and nutrients removal. The paper presents the results of research aimed at understanding the deep removal of phosphates from household wastewater. Provides a method for wastewater treatment using reinforced boot material. In this paper, we investigated metal corrosion in iron-loading materials under different operating conditions. The paper presents the results of scientific work dedicated to the removal of ammonia nitrogen from wastewater. Based on the results of research were built characteristics of the process of biological treatment with nitrification and denitrification of. The paper presents charts showing the operation of the cleaning system with nitrifying bacteria heterotrophs. The results of studies of processes of wastewater treatment from biogenic elements at small treatment plants that operate in seasonal mode are presented.
\end{abstract}

\section{Introduction}

In recent years, eutrophication processes are a serious threat to water bodies. Excess income of biogenic substances from water-collecting areas leads to the deterioration of the quality of natural waters, which is usually accompanied by changes in the ecosystem structure of water bodies.

Increased concentration of biogenic substances leads to a rapid development of bluegreen algae, reduced dissolved oxygen levels, fish kill, coastal zone overgrowing, increased complexity of water treatment.

Deterioration of water quality in water bodies is directly related to the development of anthropogenic eutrophication processes. To address this complex problem, it is necessary to minimize the discharge into water bodies of biogenic substances - nitrogen and phosphorus compounds.

Municipal wastewater is one of the main sources of biogenic matter. Currently, scientists around the world attach great attention to the development of new and improvement of existing methods for the purification of wastewater from biogenic elements.

Constructions available at wastewater treatment plants, while introducing modern technologies allow solving problems on intensification of wastewater treatment, and with minimal capital investments, they make it possible to maintain the quality of treated wastewater in accordance with the latest requirements. The quality of wastewater treatment

\footnotetext{
*Corresponding author: olga.ruzhitskaya@yandex.ru
} 
is based not only on the results of sanitary and chemical analyses, but also on a deep study of microbiological bases of processes that occur during the deep biological purification.

The issue of nutrient removal is the primary step towards improving the quality of treated wastewater and is most appropriate to the tasks of improving the ecological state of aquatic environment $[1,2]$.

\section{Treatment of wastewater from phosphate and organic contaminants}

Currently, there are many different methods for removing phosphate from waste liquid. Phosphates may be removed chemically (chemical, physico-chemical methods), biologically (biological method) through the modification of biological process of phosphorus incorporation into the cellular substance or through the biological and chemical process. In practice, there are various schemes, combining biological process and chemical precipitation. This combination of processes allows achieving a higher quality of purified water, than when applying one of them. There are schemes of bio-chemical purification, which are distinguished by the place of reagent introduction and the composition of the reagent. As far as the process of bio-chemical treatment is improved, the reagents used for this process are improved, too. The most promising are the developments of new reagents consisting of production wastes. The use of water station residual matter, extracts of brown coal ash, wastes from the manufacture of iron as reagents are studied. New reagents are developed. Great attention is given to the process of dispensing reagent [3].

A promising method of removing phosphates is a method of biological corrosion or biogalvanic method to remove phosphates from wastewater. We have conducted studies to examine this method in order to improve the efficiency of phosphates removal and intensification of the biological treatment from organic contaminants.

The beneficial effect of iron ions on the vital activity of the active sludge is well known, iron ions $\mathrm{Fe}^{3+}$ also strongly excite the bacterial growth in the active sludge.

When conducting research, the reinforced feed material was placed into the body of the aeration tank. The feed material was reinforced with iron Grade Steel 3 (low-carbon steel). The studies lasted for 6 months. To compare the results, a control aeration tank with a nonreinforced feed material was continuously operated.

The studies conducted have shown that, when using this method in the aeration tank, the efficiency of purification from phosphates is about $60-70 \%$, with the concentration of phosphates in the incoming wastewater of approximately $14 \mathrm{mg} / \mathrm{L}$. Concurrently, a significant increase in the intensity of organic contaminants was observed. An increase in the dose of the free-floating active sludge from $\approx 2.0 \mathrm{~g} / \mathrm{L}$ (when working with the non-reinforced feed material) up to $\approx 4.0 \mathrm{~g} / \mathrm{L}$ should be noted. When increasing the dose of sludge, the sludge index declined.

Such a change in the dose of sludge, sludge index and phosphate removal efficiency can be attributed to the sharp increase in the concentration of dissolved iron in the aeration tank after installing the reinforced feed material in it [4].

The comparison of the results obtained from the aeration tank with the reinforced feed material and the control (without reinforced feed material) showed an increase in the efficiency of the biological process of wastewater treatment from organic contaminants that reveals a significant intensification of the process of purification from organic contaminants by using the reinforced feed material. Charts shown in Figure 1 clearly show that after placing the reinforced feed material in the aeration tank body the removal of organic contaminants occurs more effectively. 


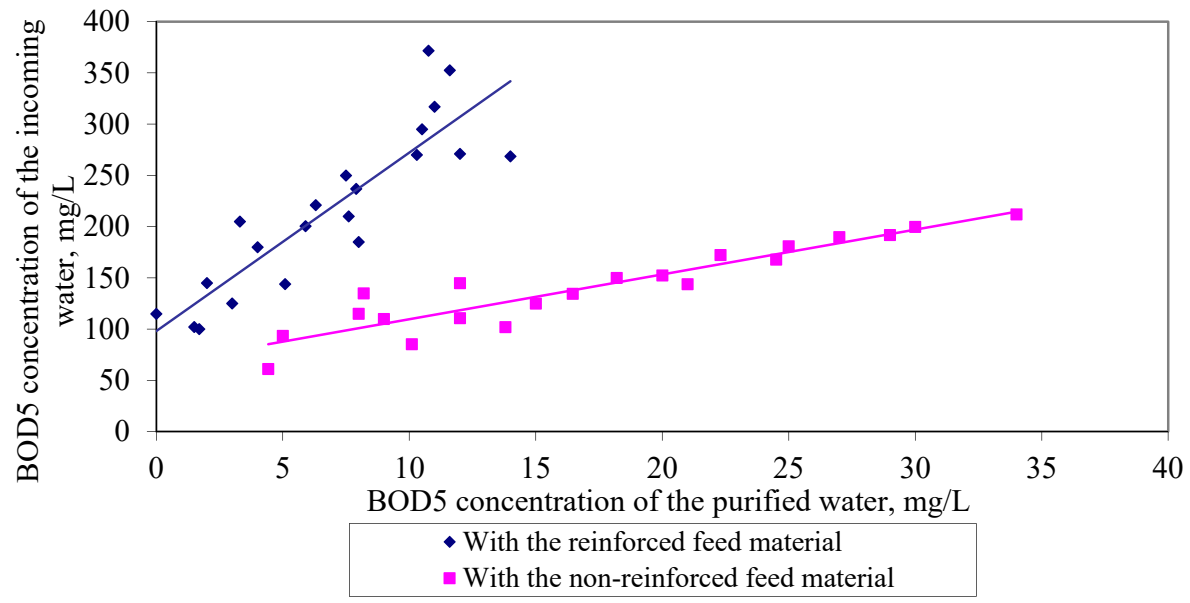

Fig. 1. The removal of organic contaminants.

Phosphorus is removed with the excessive active sludge. The "younger" is the sludge, the more intensive it grows, the more phosphorus it consumes, removing it from the water. We have recorded that after the sharp decline in the dose of free-floating sludge by $\approx 30 \%$ the phosphate removal effect significantly increases and reaches $99 \%$; therefore, in order to achieve the most complete removal of phosphates from wastewater by using the reinforced feed material, it is necessary to maintain the small age of the sludge in aeration tank, i.e., the effective removal of phosphates is due to the young, developing active sludge [5]. If the returnable active sludge is completely removed, provided the significant amount of biomass attached to the reinforced material, we get an optimal scheme for deep phosphate removal (Figure 2).

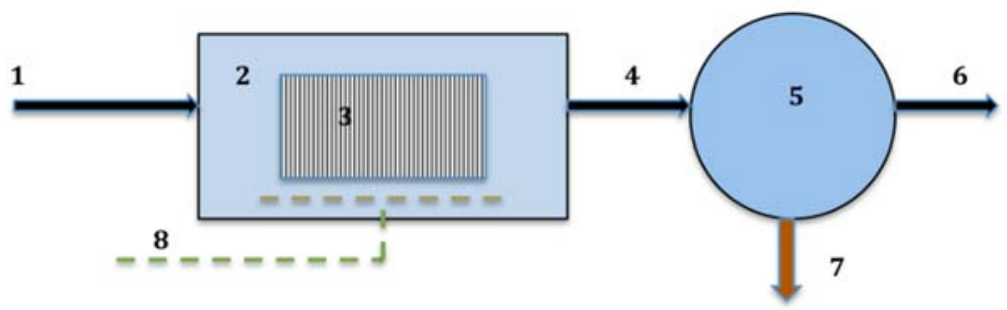

Fig. 2. The bioreactor flow chart for working with the reinforced feed material: 1 - incoming wastewater; 2 - bioreactor; 3 - reinforced feed material (in the control model - non-reinforced); 4 - a mixture of purified wastewater and biofilm; 5 - secondary clarifier; 6 - purified wastewater; 7 excessive active sludge; 8 - air.

The experiment revealed the relationship between the effect of the removal of phosphates and $\mathrm{BOD}_{5}$ of the incoming waste fluid (Figure 3 ).

The optimal concentration of organic contaminants by $\mathrm{BOD}_{5}$ in waste fluid flowing, while achieving the maximum effect of phosphate removal, ranged from 150 to $300 \mathrm{mg} / \mathrm{L}$, suggesting a biological nature of phosphate removeal in this process. To maintain the optimal conditions for the development of the specific microflora, it is necessary to maintain $\mathrm{BOD}_{5}$ of the incoming waste fluid at the level of 150-300 $\mathrm{mg} / \mathrm{L}$. Lack or excess of organic contaminants leads to a decrease in the effect of phosphate removal. With the increased content of $\mathrm{BOD}_{5} \approx 300-400 \mathrm{mg} / \mathrm{L}$ in the incoming waste fluid, a pronounced overgrowing of loading material occurs, and anaerobic zones with lack of oxygen develop, which inhibits the 
development and vitality of the specific microflora on the feed material and reduces the effect of phosphate removal [6].

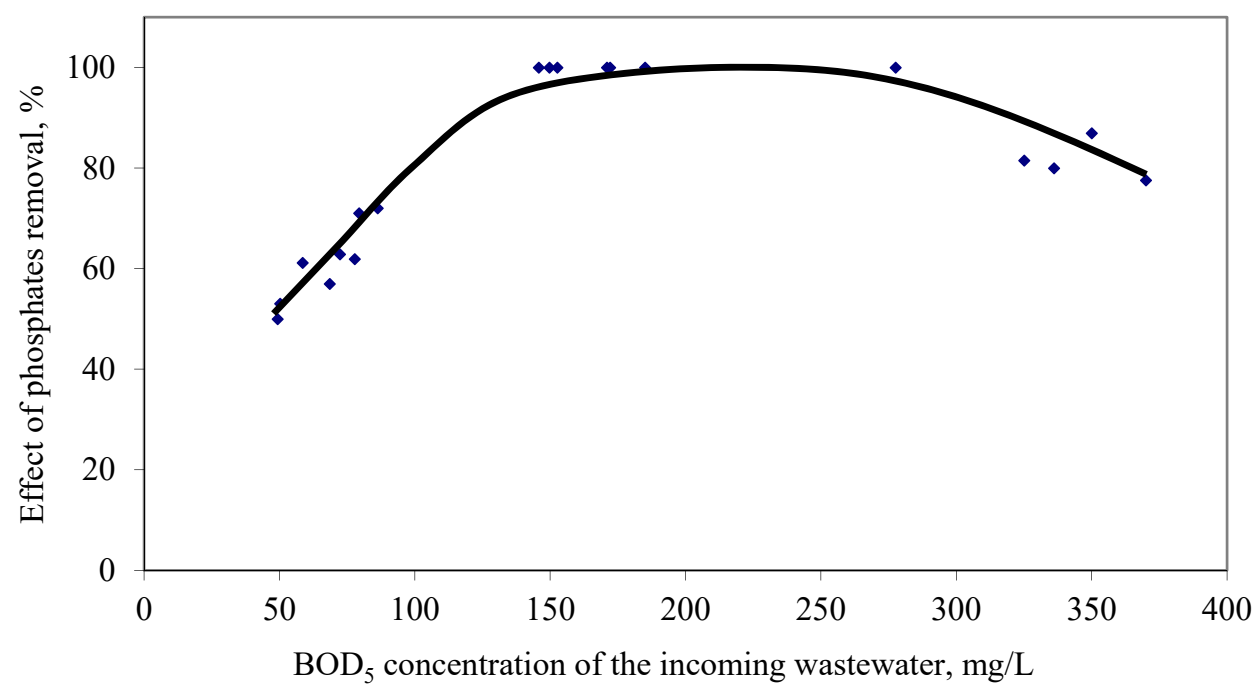

Fig. 3. The relationship between the effect of the removal of phosphates and $\mathrm{BOD}_{5}$ of the incoming waste fluid $\left(\mathrm{P}-\mathrm{PO}_{4}\right.$ concentration $\approx 4-6 \mathrm{mg} / \mathrm{L}, \mathrm{HRT}=4-6 \mathrm{~h}$ ).

\section{Removal of ammonium}

The best way of removing ammonia nitrogen from wastewater is the method of using singlesludge denitri-nitrification, combining high ammonia nitrogen removal efficiency at low cost, and the possibility of introducing this method at the existing wastewater treatment plants by their reconstruction.

When studying microbiological process of removing ammonia nitrogen from wastewater by the method of single-sludge denitrification-nitrification, the attention was primarily drawn to:

- the cause of total nitrogen decrease;

- the effect of sludge mixture reactor retention time on the qualitative and quantitative composition of the active sludge;

- microbiological conditions to optimize the reactor operation.

The research methodology provided for sampling of active sludge from all areas of the reactor with subsequent seeding of the suspension of microorganisms with the purpose of counting and detection of the nitrification activity, examination of live active sludge and examination of the fixed active sludge using light and scanning electron microscopes.

Reactor operation by the method of single-sludge denitrification-nitrification allows to achieve partial or total organic nitrogen removal. This happens only, when the sludge mixture reactor retention time is 8 to 12 hours. With a view to better understand the process, research into the microbial bases of ammonia nitrogen oxidation and border of transition to organic nitrogen oxidation was conducted [6,7].

Studies have shown that when sufficient quantities of ammonium nitrogen in wastewater percentage of organic nitrogen in the purification process remains unchanged. The complete purification of wastewater from ammonium nitrogen decreases the organic part and increases the content of ammonium component, i.e. the ammonification reaction is observed. Thus, 
when ammonium deficit, bacteria turn to the organic nitrogen. This reaction requires proteolytic enzymes, which hydrolyse proteins, peptides, etc. However, as it is known, the nitrification reactions are carried out by nitrification bacteria; they are autotrophic and have no ability to secrete proteolytic enzymes to decompose organic compounds. I.e., if an insufficient ammonium nutrition of bacteria-nitrificators, heterotrophic bacteria, which can secrete proteolyases, are included in the food chain. It should also be noted that proteolytic enzymes are poison for a living procaryotic cell, i.e. autotrophic nitrificators [8].

Studies have shown that when determining the nitrificating activity in the test reactor due to the development of autotrophic nitrificators, it turned out that this physiological group is represented extremely weak, their number is very small. When operating the reactor for 8 and 12 hours, the accumulation of nitrites and nitrates in the microbial community was virtually not observed. With the development of the microbial community in the reactor, the number of autotrophic nitrification bacteria increases somewhat, although ions of nitrites and nitrates were reliably detected only when the elective medium for autotrophic growth was inoculated with the suspension of first dilution. In numerical terms this corresponds to 10 cells per $1 \mathrm{ml}$. Thus, it is shown that ammonium starvation and organic nitrogen decomposition leads to the death of autotrophic nitrification bacteria, their number decreases significantly. When the active sludge recirculation, the number of autotrophic bacteria increases, but their activity to nitrification is not great, and they do not affect the process of ammonia nitrogen oxidation [9].

The number of heterotrophic microorganisms present in 4 areas of the reactor in different oxygen regimes is presented in Table 1 .

The analysis of this table clearly reflects the operating modes of the reactor. When operating the reactor for 12 hours, organic contamination and ammonium nitrogen loading on the active sludge is small, and hence, the number of bacteria required to oxidize these substances is little, as far as contamination decreases, their number declines. A slight increase in microorganisms is observed only in the third reactor area, but this is due to the fact that this area is supplied with an additional substrate - waste fluid. When operating the reactor for 8 hours, a sharp increase in the number of microorganisms in the aerated reactor area was observed, which is indicative of the improvement of their living conditions, though the number of bacteria in the first area is enough to start the nitrification process. When reducing the contamination load in the fourth reactor area, a decrease in the number of bacteria is also noted [10].

Table 1. The number of heterotrophic microorganisms in samples from areas of the reactor.

\begin{tabular}{|c|c|c|c|c|}
\hline \multirow{2}{*}{$\begin{array}{c}\text { Sample No. } \\
\text { (reactor area) }\end{array}$} & \multicolumn{3}{|c|}{ Number of microorganisms, cells/ml } \\
\cline { 2 - 5 } & \multicolumn{2}{|c|}{ Retention time - 12 hours } & \multicolumn{2}{c|}{ Retention time - 8 hours } \\
\cline { 2 - 5 } & Bacteria & Fungi & Bacteria & Fungi \\
\hline 1 & $3.7 \times 10^{7}$ & $4 \times 10^{6}$ & $10 \times 10^{7}$ & $0.3 \times 10^{5}$ \\
\hline 2 & $3.2 \times 10^{7}$ & No & $39.3 \times 10^{7}$ & $1.0 \times 10^{5}$ \\
\hline 3 & $4.2 \times 10^{7}$ & No & $40.8 \times 10^{7}$ & No \\
\hline 4 & $2.7 \times 10^{7}$ & No & $27.2 \times 10^{7}$ & \\
\hline
\end{tabular}

For a more detailed examination of the biological processes of removing nitrogen compounds in the single-sludge denitrification-nitrification system, microscopic studies using light and scanning electron microscopes were conducted. Living culture was studied on a light microscope immediately after sampling and then fixed with gluteraldehyde.

Studies on the light microscope_with a magnification of $\times 150$ demonstrated that the active sludge of this system in the reactor of single-sludge denitrification-nitrification in all the studied modes is represented mainly by protozoa and rotifers. The prevailing rotifers include Pilodina, Callidina, Notommata, Cathypna and protozoa - Vorticella (microstoma, convallaria, carchesium) and Opercularia glomerata. 
Thus, according to the research carried out on a light microscope, the preferred option remains the reactor operation mode with the sludge retention time of 8 hours.

\section{Conclusions}

The use perspectiveness of the biological corrosion method for phosphate removal from wastewater is proved. Based on the research conducted, we can conclude that the reinforced feed material beneficially effects the efficiency of phosphate removal from wastewater and has an intensifying effect not only on phosphate removal processes, but also on the removal of organic contaminants from wastewater. This purification method can be recommended not only to increase the effect of phosphate removal, but also to intensify biological treatment of wastewater in general.

Based on the studies conducted, microbiological inoculations have proved that the ammonia nitrogen oxydation in the reactor running under the scheme of single-sludge denitrification-nitrification is done by the heterotrophic nitrification bacteria. With deficiency of carbon and ammonia supply, these bacteria are able to secrete proteolytic enzymes to decompose complex organic compounds - proteins, peptides, etc. and, thus, to produce deep treatment of wastewater from various organic compounds and ammonia nitrogen. From the options considered, preference is given to the experiment with the sludge retention time in the reactor of 8 hours, since in this case the number of microorganisms is optimal for the treatment of wastewaters, and their ability to nitrification in this operation mode is the best.

\section{References}

1. M. Shourian, A. Moridi, M. Kaveh, Water Sci. and Technol., 74, 6, 1376-1385 (2016)

2. G. Li, F. Xie, J.Zhang, J. Wang, Y. Yang, R. Sun, Water Sci. and Tech., 74, 6, 12661273 (2016).

3. E. Gogina, A. Pelipenko, MATEC Web of Conf., 73, 03007 (2016)

4. N. Makisha, Procedia Eng., 165, 1087-1091 (2016)

5. O. Ruzhitskaya, O. Yantsen, Int. J. of App. Eng. Res., 11, 5, 3496-3498 (2016).

6. H. Jae-Hoon, J. Church, L. Seung-Jin, P. Jungsu, and L. W. Hyoung, Env. Eng.Sci., 33, 11, 882-897 (2016)

7. Y. Yang, F. Tang, X. Su, H. Yin, F. Ge, Water Sci. and Tech., 74, 11, 2727-2735 (2016)

8. H. Wang, Z.Zou, X. Xiao, D. Chen, K. Yan, Wat. Sci and Tech, 73, 11, 2689-2696 (2016)

9. N. Makisha, E3S Web of Conf., 6, 01002 (2016)

10. N. Makisha, D.Semenova, MATEC Web of Conf., 144, 04016 (2018) 